JOURNAL of

MAINE MEDICAL CENTER Journal of Maine Medical Center

\title{
Building Innovation Capacity in a Learning Health System: The Innovation Cohort Experience
}

Jennifer Monti

Maine Medical Center

Et al.

Follow this and additional works at: https://knowledgeconnection.mainehealth.org/jmmc

Part of the Other Medicine and Health Sciences Commons

\section{Recommended Citation}

Monti, Jennifer and Sanderson, Owen (2021) "Building Innovation Capacity in a Learning Health System: The Innovation Cohort Experience," Journal of Maine Medical Center. Vol. 3 : Iss. 2 , Article 11.

Available at: https://knowledgeconnection.mainehealth.org/jmmc/vol3/iss2/11 https://doi.org/10.46804/ 2641-2225.1091

The views and thoughts expressed in this manuscript belong solely to the author[s] and do not reflect the opinions of the Journal of Maine Medical Center or MaineHealth.

This Innovation Highlight is brought to you for free and open access by Maine Medical Center Department of Medical Education. It has been accepted for inclusion in the Journal of Maine Medical Center by an authorized editor of the MaineHealth Knowledge Connection. For more information, please contact Dina McKelvy mckeld1@mmc.org.

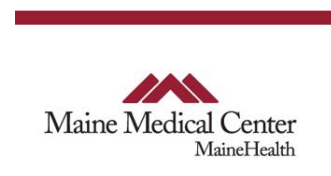




\section{Building Innovation Capacity in a Learning Health System: The Innovation Cohort Experience}

\section{Acknowledgements}

We would like to acknowledge Dr. Peter Bates, current interim dean at Tufts, who supported this early work as the Chief Academic Officer (CAO) at Maine Medical Center, and Dr. Doug Sawyer for supporting Dr. Monti's early efforts during his time as chief of the cardiovascular service line. We would also like to acknowledge Drs. Jordan Peck and Omar Hassan for their early support through the Center for Performance Improvement, and the Division of Cardiology at MMC under Dr. Marco Diaz, for supporting Dr. Monti's work. Our deepest gratitude is reserved for the remarkable people across MaineHealth who joined the cohort. We are grateful for their trust, insights, and friendship, and continue to be inspired by our colleagues ability to invent with empathy.

Authors

Jennifer Monti and Owen Sanderson 


\title{
INNOVATION HIGHLIGHT
}

\section{Building Innovation Capacity in a Learning Health System: The Innovation Cohort Experience}

\author{
Jennifer Monti, MD, MPH, ${ }^{1}$ Owen Sanderson, $\mathrm{MA}^{2}$ \\ ${ }^{1}$ Maine Medical Center, Department of Cardiology, Portland ME, ${ }^{2}$ IA Collaborative, Chicago, IL
}

\begin{abstract}
Introduction: People with ideas about how to improve products and services often benefit from a structured process to test their ideas. The Innovation Cohort was developed to empower staff at MaineHealth to create solutions to unmet needs. This article describes the progress and perspectives gained over 3 years of the program.
\end{abstract}

Methods: $\quad$ The Innovation Cohort was loosely modeled on the National Science Foundation's iCorp that emphasizes customer discovery and hypothesis testing early during development. Innovation Cohort applicants proposed a specific problem and answered 5 basic questions related to solving that problem. Selected participants shared readings and attended 5 in-person meetings focused on customer discovery, developing prototypes, and testing hypotheses at each step of development. In 5 cycles over 30 months, 62 people applied, and 24 projects were incubated.

Results: $\quad$ The projects independently attracted $\$ 130,000$ in investments to advance the work. Projects were developed into commercial products for sale, published, and continue to iterate in a local accelerator. Connections formed among people and institutions that have not routinely collaborated on projects of this type.

Discussion: The Innovation Cohort model is useful for cultivating people and ideas that may impact care, education, and research across a health care system. The most significant challenge to scaling this type of work is not funding, but rather to retain the high intellectual friction and low social friction required to cultivate ideas.

Conclusions: With a structured but approachable process, a small team that values ideas and progress over hierarchy, and a little capital that can be deployed quickly, ideas can interact and progress in a learning health system.

Keywords: $\quad$ innovation, infrastructure, inventions

$\mathrm{T}$ he Innovation Cohort developed from the observation that MaineHealth, and Maine Medical Center in particular, has the highest concentration of individuals trained in science, technology, engineering, and math in the state. People at MaineHealth have deep clinical expertise and experience delivering care through many different channels, and they are uniquely positioned to describe pain points and "the tools they wish they had." However, people are not routinely exposed

Correspondence: Jennifer Monti, MD, MPH

Department of Cardiology, Maine Medical Center

22 Bramhall Street, Portland, ME 04102

jmonti@mmc.org to a structured innovation process to help turn their remarkable expertise and insight into novel pathways, products, or services to solve problems seen every day in practice. Innovation teams or groups have sprung up at health systems across the United States and vary widely in resourcing and scope. ${ }^{1}$

The structure of the Innovation Cohort was generally based on the framework of the innovation immersion experience deployed at large academic centers through the National Science Foundation. ${ }^{2}$ Design-thinking principles were embedded through the process to increase the likelihood that if a good idea was identified, validated, and tested, it 
would be more likely to experience uptake by the appropriate audience.

\section{METHODS}

Aware of the science that shows diverse groups are more effective, the team was mindful to build cohorts that reflected a range of job types, problems to be studied, geographies, and experiences.

Individuals with an idea, or an identified pain point, applied to the Innovation Cohort by answering 4 questions:

1. Describe the unmet clinical need and/or problem you are trying to solve;

\section{Describe what you are developing;}

3. Describe the size of the opportunity and how it will be measured; and

4. Describe how seed funding could accelerate the work.

Projects were selected by a group of evaluators from the MaineHealth Center for Performance Improvement and, subsequently, by a group embedded in the MaineHealth Innovation Center.

The Innovation Cohort met as a full group 5 times over 10 weeks, and individual projects would meet with the Innovation Cohort founder as needed. Full group meetings lasted 1 hour and were scheduled to fit into a care team member's busy work schedule. Topics discussed in each session included problem identification, problems worth solving, how to interview for meaning, customer discovery, rapid prototyping, intellectual property, and perfecting the pitch. Texts included The Innovator's Dilemma by Clayton Christensen ${ }^{3}$, The Startup Manual by Steve Blank and Bob Dorf ${ }^{4}$, The Fortune at the Bottom of the Pyramid by C.K. Prahalad ${ }^{5}$, and a range of curated articles and videos. In addition to tests and in-person meetings, participants met regularly with the Innovation Cohort director during "office hours." Participants were put in quick contact with stakeholders to gain quick, tangible feedback to improve on their ideas.

\section{RESULTS}

Of the 24 incubated projects, 18 involved potential products that clinicians invented to solve a problem they see in daily clinical practice. Of these, 5 projects focused on internal process problems that employees hoped to solve through an innovation channel, and 1 was a brainstorming project. Of the participants, 10 were physicians and the remainder included nurses, social workers, physical therapists, students, a PhD candidate, a chiropractor, and a director of nutrition at a MaineHealth hospital.

Projects in the Innovation Cohort included medical device ideas, software ideas, process improvements, and new program initiation. The projects required development of quick prototypes for validation. The type of prototype required varied tremendously depending on the nature of the problem being solved. Examples of funded work, and the current stage of development, are described in Table 1.

We attempted to use local expertise where possible, both for speed and to generate connections between regional assets. The University of Southern Maine (USM) has proved to be a useful partner for this purpose. For example, a pediatric surgeon at MaineHealth has worked with Dr. Asheesh Lanba at USM to develop the engineering drawings for a clinical grade prototype of a device to close a gastrocutaneous fistula through minimally invasive means. The patent application for this novel medical device now includes 2 institutions: Maine Medical Center and USM. This filing is the first of its kind between these local institutions.

A nurse navigator prototyped her hospital gown redesigns at Common Threads (www. commonthreads.org), a local sewing school focused on helping immigrant communities develop skill sets. The connections between organizations across our region thrives on use-case projects like these gowns. We learn, and we connect, by doing. Twenty-four projects engaged hundreds of internal experts and external organizations, ranging from academic (Massachusetts Institute of Technology, Yale University, USM, Case Western Reserve University) to community-based (YMCA, Sea Change Yoga) to local prototypers and companies interested in helping to advance the work (Dale Medical, Looma, Cliexa, Standard Textile). 
Table 1. Examples of Work Funded Through the Innovation Cohort

\begin{tabular}{|c|c|c|}
\hline Title & Job type of project lead & Stage of project \\
\hline $\begin{array}{l}\text { Software to track staffing in family birthing } \\
\text { center }\end{array}$ & Nurse manager & Commercial \\
\hline Ostomies to reduce leakage & Medical student & $\begin{array}{l}\text { Pivoted to related } \\
\text { indication; commercial }\end{array}$ \\
\hline Percutaneous fistula closure & Surgery attending & In development \\
\hline Gown design for patients with brain injury & Nurse navigator & $\begin{array}{l}\text { Advanced } \\
\text { development }\end{array}$ \\
\hline $\begin{array}{l}\text { Augmented reality to train low-volume, rural } \\
\text { birth centers }\end{array}$ & Pediatric attending(s) & $\begin{array}{l}\text { Advanced } \\
\text { development }\end{array}$ \\
\hline $\begin{array}{l}\text { Biocontainment for patients suspected to have } \\
\text { COVID-19 }\end{array}$ & $\begin{array}{l}\text { Emergency department } \\
\text { attending and residents }\end{array}$ & $\begin{array}{l}\text { Advanced } \\
\text { development }\end{array}$ \\
\hline Device to clear patient airways & Nurse & In development \\
\hline Imaging of pulmonary nodules over time & Radiology attending & No longer pursuing \\
\hline $\begin{array}{l}\text { Aortic clamp to reduce acute kidney injury in } \\
\text { vascular surgery patients }\end{array}$ & Medical student & No longer pursing \\
\hline Mobile platform to visually display dietary inputs & Medical resident & $\begin{array}{l}\text { Advanced } \\
\text { development }\end{array}$ \\
\hline $\begin{array}{l}\text { Platform for rare disease patients to meet } \\
\text { remotely }\end{array}$ & Social worker & Deployed \\
\hline Movement class for new residents in Maine & Medical resident & Deployed \\
\hline
\end{tabular}

Abbreviations: COVID-19, coronavirus disease 2019.

Several projects were selected through a competitive application to participate in the formal iCorp program, funded by the National Science Foundation and administered throughout New England by the Massachusetts Institute of Technology. The "informal" or "loose" ties that form between people in venues like iCorp are the connections that drive unexpected innovation over time.

\section{DISCUSSION}

Establishing this group provided a "thinking" space for people with ideas and motivation to solve problems they see in clinical practice. The greatest challenge to scaling this type of work is not funding, but rather retaining the high intellectual friction and low social friction needed to cultivate ideas. ${ }^{6}$ One of the most substantial benefits has been for people with an interest in this type of work to find each other. Identifying peers is an essential part of building support for ideas that, on paper alone, have nowhere to go and no "need" to exist.

Five key insights and subsequent implications emerged from this work:

\section{Collisions across roles.}

Working in a cohort effectively embeds innovation science at a unique level within an organization. People in management roles are commonly exposed, in some fashion, to innovation science, whereas this exposure is less common for people in other layers of an organization. A cohort creates a venue, which creates a personal connection, which creates a network, which creates trust and further connection of nodes across a large system. 


\section{Where is the time?}

Many scientists, technologists, and physicians want to work in integrated systems that are continuous learning ecosystems. This environment can be challenging in institutions with high clinical workloads. Models like the Innovation Cohort offer contained, "bite-sized" education to curate passionate people whose commitment extends beyond their job description on paper. As projects mature and attract resources, the most important questions are: how do you retain a "flat" culture, and who has to remove barriers for an innovation culture to thrive?

\section{Problem over technology.}

Successful Innovation Cohort projects were not "technology in search of a solution." Rather, they were "problems in search of technology that might help." As expertise in understanding problems grows, MaineHealth could become an attractive partner for technology firms that are seeking important problems to solve.

\section{Intentional diversity improves thinking.}

The most important connections that emerged from the Innovation Cohort process are the relationships between people who work across MaineHealth every day. There is no reason, under most circumstances, for people from a range of job roles and experiences, like those represented in each cohort group, to meet and spend time together. However, innovation often emerges from the intersection of fields, not from deep within one specific field. These efforts require intentionally cultivated environments and do not simply form on their own.

\section{Limitations.}

Given the need for trust and conversation among projects, the Innovation Cohort is necessarily limited in size. As such, a cohort process can be part of a larger innovation infrastructure, but it will be difficult to scale as a central part of an innovation infrastructure. Importantly, different projects and different people will require different support from the person or team supporting the cohort process. The Innovation Cohort will function most effectively if there are ambassadors throughout the health system and local community who signal their interest in being approached or interviewed by project teams.

\section{CONCLUSIONS}

Innovation is often no one's "job." Members of an Innovation Cohort may be passionately committed to a "small" problem that shines very brightly for them and the patients and people they care for, but dimly on the overall priorities. Projects like those in the Innovation Cohort can serve as a helpful home for promising ideas to garner early attention and resources to increase the likelihood those ideas to connect and grow. Over time, we hope ideas progress more quickly and freely than they did before the Innovation Cohort model. The more interactions that get cultivated, the more likely a very good, resilient, scalable project will emerge to have a disproportionate impact in relevant domains of care, research, and education.

The Innovation Cohort model has been added to a portfolio of programs and services under the umbrella of the newly established Innovation Center at MaineHealth. A spring 2021 cohort is now open. An innovation elective for medical students has also been developed and is available to medical students at Tufts University and visiting students as MEDED480. People interested in learning more about current programming may contact the innovation center at innovation center@ mainehealth.org.

\section{Conflicts of interest: none}

\section{Acknowledgements:}

We would like to acknowledge Dr. Peter Bates, current interim dean at Tufts, who supported this early work as the Chief Academic Officer (CAO) at Maine Medical Center, and Dr. Doug Sawyer for supporting Dr. Monti's early efforts during his time as chief of the cardiovascular service line. Wewould also like to acknowledge Drs. Jordan Peck and Omar Hassan for their early support through the Center for Performance Improvement, and the Division of Cardiology at MMC under Dr. Marco Diaz, for supporting Dr. Monti's work. Our deepest gratitude is reserved for the remarkable people across MaineHealth who joined the cohort. We are grateful for their trust, insights, and friendship, and continue to be inspired by our colleagues ability to invent with empathy. 


\section{Monti and Sanderson: Innovation Capacity in a Learning Health System}

\section{REFERENCES}

1. Ellner AL, Stout S, Sullivan EE, Griffiths EP, Mountjoy A, Phillips RS. Health systems innovation at academic health centers: leading a new era of health care delivery. Acad Med. 2015;90(7):872-880. doi:10.1097/ACM.0000000000000679

2. NSF Innovation Corps. NSF I-Corps Team Highlights. National Science Foundation. Accessed March 30, 2021. https://www.nsf. gov/news/special_reports/i-corps/
3. Christensen CM. The Innovator's Dilemma: When New Technologies Cause Great Firms to Fail. Harvard Business Review Press; 2016.

4. Dorf S, Blank S. The Startup Owner's Manual: The Step-By-Step Guide for Building a Great Company. K \& S Ranch; 2012.

5. Prahalad C. The Fortune at the Bottom of the Pyramid: Eradicating Poverty Through Profits. Pearson India Education; 2013.

6. Clark T. The 4 Stages of Psychological Safety: Defining the Path to Inclusion and Innovation. Berrett-Koehler Publishers; 2020. 